\title{
Quantification of the Phase Transformation Kinetics in High Chromium Cast Irons Using Dilatometry and Metallographic Techniques
}

\author{
MARÍA AGUSTINA GUITAR, ANNA SCHEID, U. PRANAV NAYAK, \\ LEANDRO NAKAMURA, DIRK PONGE, DOMINIK BRITZ, \\ and FRANK MÜCKLICH
}

\begin{abstract}
Further development of high chromium cast irons (HCCI) is based on tailoring the microstructure, necessitating an accurate control over the phase transformation and carbide precipitation temperatures and can be achieved by thermal treatments (TT). To understand the underlying mechanisms controlling the transformation kinetics during the different stages of the TT, it is imperative to adjust the TT parameters to have information of the transformations occurring during non-thermal and isothermal heating cycles, since proper selection of the TT parameters ensures the optimum use of the alloying elements. In this work, the boundaries of the phase transformations for a HCCI containing 26 wt pct $\mathrm{Cr}$ for different cooling rates (continuous cooling transformation, CCT, diagram) were established by applying dilatometric measurements. Based on the CCT diagram, a temperature-time-transformation (TTT) diagram was constructed by isothermally holding the samples until complete phase transformation. For determining the initiation and finishing of the transformation, the lever rule assisted by derivatives was applied. The phases present after transformation were determined by combining $\mathrm{X}$-ray diffraction (XRD) and metallographic characterization using optical microscopy (OM) and scanning electron microscopy (SEM). Finally, the data obtained from the dilatometer was experimentally verified by isothermally heat treating some samples using laboratory furnaces. The transformed phase fraction from OM and SEM images was then correlated to the fraction obtained from the TTT diagram.
\end{abstract}

https://doi.org/10.1007/s11661-020-05808-y

(c) The Author(s) 2020

\section{INTRODUCTION}

HiGH-CHROMIUM cast irons (HCCI) containing 12-30 wt pct $\mathrm{Cr}$ and 2-3.5 wt pet $\mathrm{C}$, are extensively used for high abrasion-resistant applications such as components that manipulate and mechanically process aggregates and raw materials. ${ }^{[1-3]}$ Their wear resistance and mechanical properties mainly depend on the type, morphology and distribution of carbides, and on the nature of the supporting matrix structure which, in turn, depends on the chemical composition and on any subsequent thermal treatments (TT). ${ }^{[4-6]}$ The current

MARÍA AGUSTINA GUITAR, ANNA SCHEID, U. PRANAV NAYAK, and LEANDRO NAKAMURA are with the Department of Materials Science, Saarland University, Campus D3.3, 66123, Saarbrücken, Germany. Contact e-mail: a.guitar@mx.uni-saarland.de. DIRK PONGE is with the Max-Planck-Institut für Eisenforschung, Max-Planck-Str. 1, 40237 Düsseldorf, Germany. DOMINIK BRITZ and FRANK MÜCKLICH are with the Department of Materials Science, Saarland University and also with the Materials Engineering Center Saarland, Campus D3.3, 66123, Saarbrücken, Germany.

Manuscript submitted January 21, 2020.

Article published online May 16, 2020 trend is to expand the uses and duty life of HCCI by exploring alternative TT that would affect the type and nature of precipitates. With this in mind, microstructure tailoring must be the base for the further development of HCCI with the aim to obtain the desired performance of the material for a specific application. The goal of this approach is to find the best matrix/precipitates combination based on the nature, size and distribution of secondary carbides, which can be controlled by adjusting the temperature and annealing time at the destabilization and/or sub-critical diffusion (SCD) steps. ${ }^{[2,4]}$

In a previous work, ${ }^{[7]}$ two different TT were applied to HCCI containing 16 wt pct $\mathrm{Cr}$; the commonly used destabilization/quenching (Q) and a newly proposed multi-step TT, which includes destabilization/subcritical-diffusion/quenching $(S C D+Q)$. Destabilization of the austenite is a frequent practice in the hardening of $\mathrm{HCCI}$, where the precipitation and growth of secondary carbides (SC) occur together with the redistribution of the carbon within the austenitic matrix. ${ }^{[8]}$ A subcritical heat treatment, usually carried out at lower temperatures $\left(200{ }^{\circ} \mathrm{C}\right.$ to $\left.650{ }^{\circ} \mathrm{C}\right)$ for longer times (up to 12 
hours), has been often implemented after destabilization for decreasing the amount of retained austenite and increase the resistance to spalling. ${ }^{[9-11]}$ However, this step might lead to microstructural changes, which might be beneficial for the material properties, as in the case of the HCCI containing $16 \mathrm{wt}$ pct $\mathrm{Cr}$ subjected to the $\mathrm{SCD}+\mathrm{Q}$ treatment. $^{[7]}$

Guitar et $a l .{ }^{[7]}$ observed a significant difference in the wear rate when the final microstructure, composed by martensite and secondary carbides of the $\mathrm{M}_{7} \mathrm{C}_{3}$ type, was obtained by applying the different TT ( $Q$ and $\mathrm{SCD}+\mathrm{Q})$. The SCD $+\mathrm{Q}$ sample showed an improvement in the wear rate of 69 pct in comparison to the $Q$ sample. This behaviour can be only partially related to the size of the secondary carbides, which were slightly larger in former. However, other features might influence the behaviour, as is the case of the supporting matrix, whose interaction with the carbides must be thoroughly evaluated. The final microstructure after each step of the multi-step TT is highly dependent on the material chemical composition, temperature and time of the treatment, and the prior thermal history. ${ }^{[2,9]}$ Thus, a controlled microstructure ensuring the optimal balance between the tribological behaviour and fracture toughness must be found for each particular case. In other words, for good abrasion resistance of HCCI, a martensitic matrix is desired and a pearlitic matrix must be avoided ${ }^{[9,12]}$ whereas, an austenitic matrix might lead to maximum toughness. ${ }^{[13]}$

Tailoring the microstructure in HCCI requires an accurate control over the phase transformation and carbide precipitation temperatures and a deep understanding of the mechanisms controlling the transformations kinetics. To understand the new configurations in these materials, the new microstructures must be thoroughly studied and correlated to the improved physical properties. For these reasons, it is highly important to adjust the TT parameters to have information of transformations occurring during non-isothermal and isothermal heating cycles, since the proper selection of TT parameters ensures the optimum use of the alloying elements.

Dilatometry is a powerful tool for determining solid-solid phase transformations in metals, by registering dimensional changes resulting from the phase transformations as a function of temperature and time. The dimensional changes occurring during an isothermal reaction are considered to be proportional to the volume fraction transformed. ${ }^{[14]}$ This technique also allows the determination of transformation temperatures during heating or cooling, which are essential in the planning and designing of many industrial processes. Continuous cooling transformation (CCT) and temperature time transformation (TTT) diagrams are graphical representations of the temperature and time data related to the transformations occurring in the material by the application of thermal cycles. Knowing the phase transformation boundaries will help to set the best parameters for designing the optimal multi-step TT. The TTT diagrams in particular will provide reliable data for setting the parameters corresponding to the SCD step, where the phase transition and hardening dynamics in HCCI lack a systemic study.

In this work, the CCT and TTT diagrams corresponding to HCCI containing 26 pet $\mathrm{Cr}$ were constructed using dilatometry techniques. The boundaries for the phase transformation were determined after analysing the dimensional changes as a function of the temperature. The resulting phases were determined by X-ray diffraction and microstructural characterization using optical microscope (OM) and scanning electron microscope (SEM). After constructing the TTT diagram, the fraction of the transformed phases were experimentally verified by heating some samples to a defined temperature for different times. The transformed phase fraction was determined using image analysis from OM and SEM images.

\section{MATERIALS AND METHODS}

HCCI containing 26 wt pet $\mathrm{Cr}$ was melted in an arc furnace and cast in cubic sand moulds for solidification. The chemical composition was determined by emission spectroscopy using a GNR Metal Lab 75/80 Optical Emission Spectroscope and is listed in Table I From the as-cast ingot casting, several plates with an area of 50 $\mathrm{mm} \times 45 \mathrm{~mm}$ and a thickness of $9 \mathrm{~mm}$ were sectioned with a Struers Discotom-6 water cooled abrasive cut-off wheel. From these plates, cylindrical dilatometric test specimens with a diameter of $4 \mathrm{~mm}$ and a length of $9 \mathrm{~mm}$ were machined by electrical discharge machining.

The initial microstructure (Figure 1), i.e. the as-cast condition, consists of $\mathrm{M} 7 \mathrm{C} 3$ (M: Fe, Cr) eutectic carbides embedded in an austenitic matrix. The high $\mathrm{Cr} / \mathrm{C}$ ratio (10.5) ensures that the austenitic matrix does not undergo partial decomposition (to ferrite/pearlite) during solidification. ${ }^{[15]}$ Additionally, a martensitic region is present at the carbide/matrix interface, which was formed during casting as a consequence of $\mathrm{C}$ and $\mathrm{Cr}$ depletion. The eutectic carbides (EC) will remain unchanged after the TT, ${ }^{[7]}$ whereas the carbide precipitation and microstructural modification will occur in the austenitic and martensitic region.

The dilatometric measurements were performed using two fully computer controlled DIL $805 \mathrm{~A} / \mathrm{D}$ quenching and deformation dilatometers by TA Instruments (constructed in 1996 and 2013) with a theoretical resolution of $\pm 0.05 \mu \mathrm{m}$ and $0.05^{\circ} \mathrm{C}$. The sample temperature was measured by type $\mathrm{S}$ thermocouples (PtRh90/10-Pt100 pct) welded in the mid-length of the sample by spot welding, whereas the dimensional changes during the TT cycle were transmitted by two quartz push rods. The treatments were done under argon flow at a pressure of 0.2 bar. Different heating/cooling cycles were performed for the construction of CCT and TTT diagrams, as shown in Figure 2. The temperatures for the TT cycle were selected based on a previous work, where a multi-step TT was applied for microstructure tailoring of HCCI containing 16 pet $\mathrm{Cr} .{ }^{[7]}$ For the construction of the CCT diagrams, the samples were heated up to 980 ${ }^{\circ} \mathrm{C}$ with a $0.25{ }^{\circ} \mathrm{C} / \mathrm{s}$ heating rate, held for 1.5 hours and then cooled down to room temperature at eight different 
Table I. Chemical Composition of the HCCI

\begin{tabular}{lccccccccccc}
\hline Element & $\mathrm{C}$ & $\mathrm{Cr}$ & $\mathrm{Si}$ & $\mathrm{Mn}$ & $\mathrm{Ni}$ & $\mathrm{Mo}$ & $\mathrm{S}$ & $\mathrm{P}$ & $\mathrm{Cu}$ & $\mathrm{Fe}$ \\
\hline Weight Percent & 2.53 & 26.6 & 0.37 & 0.66 & 0.26 & 0.24 & 0.04 & 0.01 & 0.03 & 69.26 \\
\hline
\end{tabular}
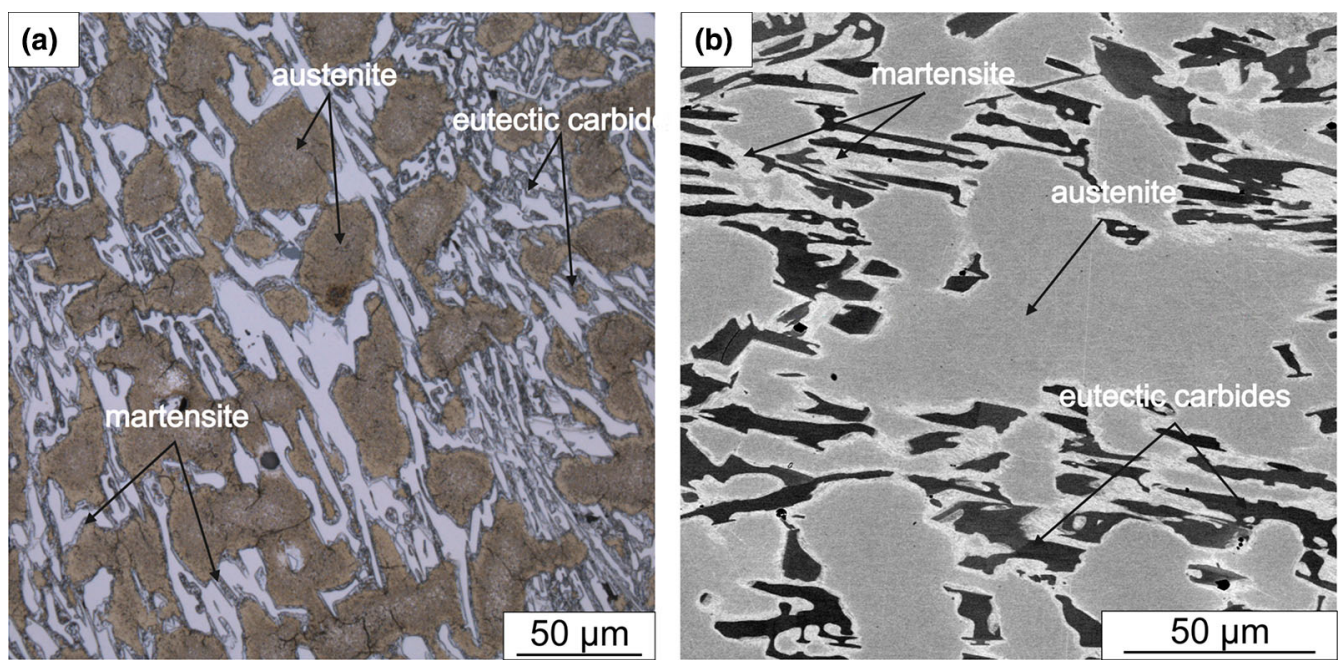

Fig. 1-HCCI_26 petCr as-cast microstructure as represented by $(a) \mathrm{OM}$ and (b) SEM. Eutectic carbides are of the $\mathrm{M}_{7} \mathrm{C}_{3}$ type embedded in an austenitic matrix. A martensitic region formed at the carbide/matrix interface resulting from $\mathrm{C}$ and $\mathrm{Cr}$ depletion.
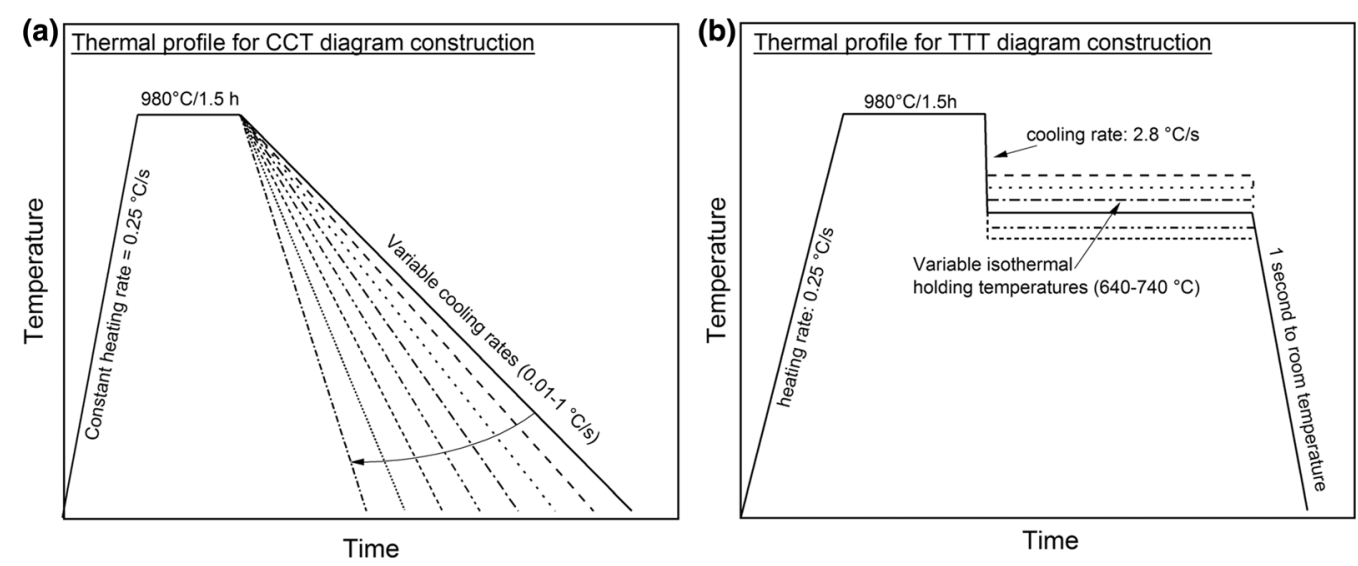

Fig. 2-Schematic thermal profile used for $(a)$ non-isothermal and (b) isothermal tempering analysis, for the construction of CCT and TTT diagrams, respectively.

cooling rates $\left(0.01{ }^{\circ} \mathrm{C} / \mathrm{s}\right.$ to $\left.1{ }^{\circ} \mathrm{C} / \mathrm{s}\right)$, as shown in Figure 2(a). For the TTT diagrams, the samples were heated up to $980{ }^{\circ} \mathrm{C}$ with a $0.25^{\circ} \mathrm{C} / \mathrm{s}$ heating rate and held for 1.5 hours. The samples were then cooled down at $2.8{ }^{\circ} \mathrm{C} / \mathrm{s}$ up to the desired temperature $\left(640{ }^{\circ} \mathrm{C}-740\right.$ ${ }^{\circ} \mathrm{C}$ ) and cooled down to room temperature after complete transformation, as shown in Figure 2(b). For each condition, four experiments were performed in order to calculate the dispersion of the obtained transformation fractions and temperatures. The transformation start and finishing point, as well as further transformed phase fractions between start and finishing were determined by the application of the lever rule ${ }^{[14,16]}$ using a commercially available analysis software, Origin 9.

Phase analysis was performed by X-ray diffraction (XRD) with a PANalytical MPD X-ray diffractometer. The diffractograms were obtained using a symmetrical $\theta-\theta$ geometry configuration and a $\mathrm{Co} \mathrm{K} \alpha / \mathrm{Cu} \quad \mathrm{K} \alpha$ radiation. The incident and diffracted optical geometries were parallel, and the diffraction angle $(2 \theta)$ was varied from 30 to $130 \mathrm{deg}$ for the as-cast condition, 35 to $140 \mathrm{deg}$ for the CCT and TTT samples, and 30 to $120 \mathrm{deg}$ for the experimental verification, with a step size of 0.013 and a 50 seconds/step rate. The applied voltage and current were $40 \mathrm{kV}$ and $40 \mathrm{~mA}$, respectively. For the 
phase identification and indexing, the High Score Plus software and ICDD Database were used.

For the metallographic preparation, the samples were mounted in conductive resin in the longitudinal direction and then ground until the centre of the sample was reached. The specimens were prepared using the standard metallographic methods. ${ }^{[17,18]}$ Polished specimens were etched for 5-15 seconds with a modified Nital etching solution $\left(97 \mathrm{~mL}\right.$ distilled $\mathrm{H}_{2} \mathrm{O}, 3 \mathrm{~mL} \mathrm{HNO}_{3}, 0.5$ $\mathrm{mL} \mathrm{HCl}$ ). The microstructure after the dilatometric test was observed by OM using a Leica CTR6000 microscope, which includes a Jenoptic CCD Camera for image acquisition; and SEM using a FE-SEM Helios Nanolab 600 (FEI company) working with an acceleration voltage of $10 \mathrm{kV}$ and a $1.4 \mathrm{nA}$ beam current. For a proper contrast between the phases, a high-sensitivity solid-state backscattered electron detector (vCD) was used.

\section{A. Process for the Experimental Verification}

Three samples were heat treated in the laboratory to experimentally verify the results of phase transformation obtained by dilatometry. The samples were subjected to the TT shown in Figure 2(b) and held at $640{ }^{\circ} \mathrm{C}$ for different times, as indicated latter in Table III, in order to obtain specific fractions of the transformed phase.

After the TT, the samples were metallographically prepared and etched with Nital for 5 seconds and analysed using OM, SEM and XRD. For each sample, three random $\mathrm{OM}$ and three SEM images were selected and binarized using the A4i C image analysis software by Aquinto AG. As a first step, the fraction of EC was determined from OM images using the fully transformed sample at $680{ }^{\circ} \mathrm{C}$ and used as a reference, since the EC are not modified during the TT and its fraction remains unchanged. The remaining matrix phase fraction was set as 100 pct transformation and the analysed samples phase fraction was compared to this reference by the rule of three. For the transformed fraction calculated from SEM micrographs, a reference for the EC fraction was not necessary, since a proper contrast between the phases was observed. Finally, the phase fraction of ferrite/pearlite was measured using quantitative image analysis using the $\mathrm{A} 4 \mathrm{i}$ (C) image analysis software after segmentation of OM and SEM images.

\section{RESULTS AND DISCUSSION}

\section{A. Construction of the CCT Diagrams}

Figure 3 shows the dilatometric curves for three different cooling rates after applying the TT described in Figure 2(a). For the fastest cooling rates $\left(1^{\circ} \mathrm{C} / \mathrm{s}\right.$ and $\left.0.2^{\circ} \mathrm{C} / \mathrm{s}\right)$, only one phase transformation occurred at a relatively low temperature (Figure 3(a)). Since the martensite start temperature $\left(M_{\mathrm{s}}\right)$ is defined as the minimum in the curve of the change in length as a function of temperature, ${ }^{[19]}$ the minimum at this dilation curve was identified as the $M_{\mathrm{s}}$. $M_{\mathrm{s}}$ was determined to be $223 \pm 11,240 \pm 20$ and $195 \pm 4{ }^{\circ} \mathrm{C}$ for the cooling rates
$1{ }^{\circ} \mathrm{C} / \mathrm{s}, 0.2^{\circ} \mathrm{C} / \mathrm{s}$ and $0.13{ }^{\circ} \mathrm{C} / \mathrm{s}$, respectively, as indicated in Figure 4. The martensite finishing temperature $\left(M_{\mathrm{f}}\right)$ was not detected during the measurement, which might indicated that $M_{\mathrm{f}}$ finds at lower temperatures (below room temperature). For this reason, the martensite phase fraction cannot be estimated.

Two transformations can be observed when an intermediate cooling rate $\left(0.13{ }^{\circ} \mathrm{C} / \mathrm{s}\right)$ is applied (Figure 3(b)), one at high temperature (between 600 ${ }^{\circ} \mathrm{C}$ and $\left.700{ }^{\circ} \mathrm{C}\right)$ and other at low temperature $\left(\sim 200^{\circ} \mathrm{C}\right)$, which might correspond to the ferrite and carbides ${ }^{[1]}$ (probably in the form of pearlite), and a low amount of martensite, respectively. Lower cooling rates (Figure 3(c)) showed a single-phase transformation at higher temperatures (between $600{ }^{\circ} \mathrm{C}$ and $800{ }^{\circ} \mathrm{C}$ ). The emerging phase is also expected to be ferrite and carbides (probably in the form of pearlite). The phase fraction as a function of the temperature for the high-temperature transformation was determined by applying the lever rule ${ }^{[16]}$ driven by derivatives (first and second) of the change in length as a function of temperature. Since solid phase transformations are generally asymptotic functions, the phase transformation boundaries as a function of the temperature, represented as the 5 and 95 pct transformed phase fraction, are indicated in the CCT diagram of Figure 4. Additionally, Table II indicates the temperature and times for the transformed phase fraction corresponding to each cooling rate.

The CCT diagram shows the hardenability for the HCCI_26 pct Cr. It shows the minimum cooling rates necessary for maximum hardenability produced by austenite/martensite transformation. A CCT diagram of a HCCI with similar chemical composition (2.6 pct C-0.8 pct Si-0.6 pet Mn-27.8 pct Cr) as the one tested in this work can be found in Reference 10. In the CCT diagram found in the literature, the destabilization was done at $1010{ }^{\circ} \mathrm{C}$, i.e. $30{ }^{\circ} \mathrm{C}$ higher than the applied in Figure 2(a). It is known that the higher the destabilization temperature, the lower the Ms, as a consequence of remaining carbon content in the austenite. ${ }^{[9,10]}$ Besides the differences in the applied TT and chemical composition, some similitudes can be observed in both CCT diagrams. Ms is found to be around $200{ }^{\circ} \mathrm{C}$ in both cases, with a slight increasing of Ms for slower cooling rates in the case of CCT diagram shown in Reference 10. Phase transformation at higher temperatures is observed for cooling rates of $0.13{ }^{\circ} \mathrm{C} / \mathrm{s}$, whereas for cooling rates of $0.15^{\circ} \mathrm{C} / \mathrm{s}$ or faster, the microstructure results in secondary carbides and martensite with some retained austenite, in both cases. The temperature boundaries for the phase transformation, i.e. for the austenite to ferrite + carbide transformation, is also similar being in the range of $750{ }^{\circ} \mathrm{C}$ to $600{ }^{\circ} \mathrm{C}$. Furthermore, Amorin et $a l .^{[1]}$ found the upper and lower critical points for the austenite to ferrite transformation in HCCI with 3.08 pet C-0.66 pet Si-0.57 pet Mn-26 pet Cr during cooling were $707{ }^{\circ} \mathrm{C}$ and $614{ }^{\circ} \mathrm{C}$, respectively. Other CCT diagram published by Maratray ${ }^{[20]}$ shows the Ms at a higher temperature $\left(300{ }^{\circ} \mathrm{C}\right)$, which rises for lower cooling rates. The same tendency and same temperature ranges for the transformation boundaries can be 

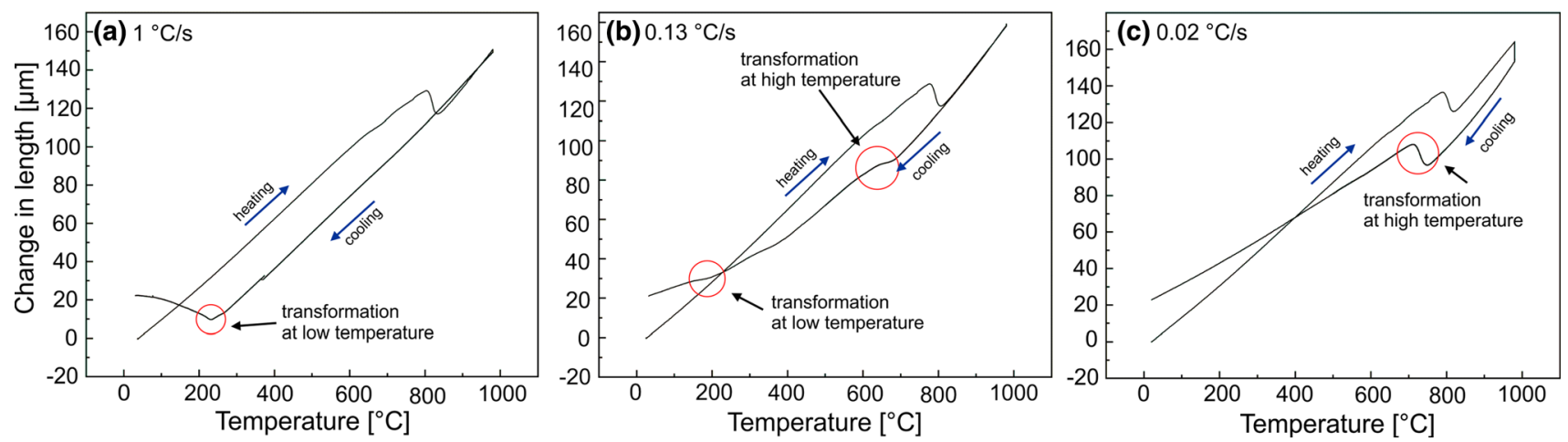

Fig. 3- Change in length as a function of temperature for different cooling rates, $(a) 1{ }^{\circ} \mathrm{C} / \mathrm{s},(b) 0.13{ }^{\circ} \mathrm{C} / \mathrm{s}$ and $(c) 0.02{ }^{\circ} \mathrm{C} / \mathrm{s}$ showing the phase transformation at different stage of cooling.
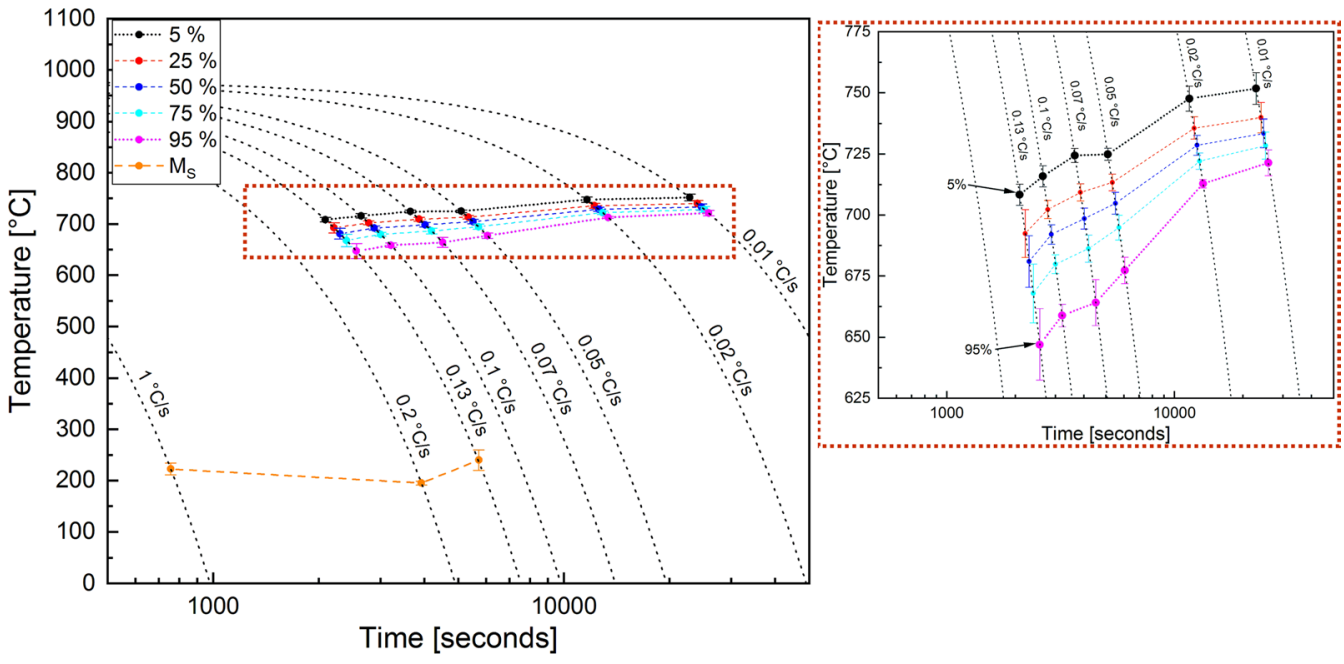

Fig. 4 - CCT diagram corresponding to the HCCI_26Cr obtained from dilatometric measurements.

Table II. Temperature and Time Corresponding to Different Phase Fractions Transformed at the Different Cooling Rates

\begin{tabular}{|c|c|c|c|}
\hline Cooling Rate $\left({ }^{\circ} \mathrm{C} / \mathrm{s}\right)$ & Phase Fraction (Pct) & Temperature $\left({ }^{\circ} \mathrm{C}\right)$ & Time (s) \\
\hline \multirow[t]{3}{*}{0.13} & 5 & $708 \pm 4$ & $2090 \pm 3$ \\
\hline & 50 & $681 \pm 11$ & $2300 \pm 81$ \\
\hline & 95 & $647 \pm 14$ & $2561 \pm 111$ \\
\hline \multirow[t]{3}{*}{0.1} & 5 & $716 \pm 4$ & $2642 \pm 44$ \\
\hline & 50 & $692 \pm 4$ & $2880 \pm 41$ \\
\hline & 95 & $659 \pm 5$ & $3212 \pm 45$ \\
\hline \multirow[t]{3}{*}{0.07} & 5 & $724 \pm 3$ & $3649 \pm 40$ \\
\hline & 50 & $698 \pm 4$ & $4019 \pm 61$ \\
\hline & 95 & $664 \pm 9$ & $4513 \pm 135$ \\
\hline \multirow[t]{3}{*}{0.05} & 5 & $725 \pm 2$ & $5103 \pm 49$ \\
\hline & 50 & $705 \pm 5$ & $5505 \pm 90$ \\
\hline & 95 & $677 \pm 5$ & $6055 \pm 109$ \\
\hline \multirow[t]{3}{*}{0.02} & 5 & $748 \pm 5$ & $11,628 \pm 255$ \\
\hline & 50 & $729 \pm 4$ & $12,569 \pm 206$ \\
\hline & 95 & $713 \pm 2$ & $13,358 \pm 85$ \\
\hline \multirow[t]{3}{*}{0.01} & 5 & $752 \pm 6$ & $22,834 \pm 648$ \\
\hline & 50 & $733 \pm 6$ & $24,660 \pm 581$ \\
\hline & 95 & $721 \pm 5$ & $25,850 \pm 535$ \\
\hline
\end{tabular}

observed here. Chemical composition (especially $\mathrm{C}$ and Si content), as well as the previous thermal history, have a huge impact on the transformation kinetics and in the final phase composition of the material. Even though the CCT diagrams for similar chemical compositions show a comparable data, for a proper evaluation of a 
determined material and its further microstructural tailoring, the transformation boundaries must be evaluated.

\section{Microstructural and phase analysis of the CCT} samples

Three samples (1, 0.13 and $0.02{ }^{\circ} \mathrm{C} / \mathrm{s}$ ) showing different behaviour in the dilation curves during cooling (Figure 3) were selected for phase and microstructural analysis, with the aim of verifying the phases present after the transformation. All micrographs are expected to show the EC of the type $\mathrm{M}_{7} \mathrm{C}_{3}$ (Figure 1) which are formed during casting and remain unaffected by heat treatments. $^{[3,7]}$ Additionally, during the destabilization at $980{ }^{\circ} \mathrm{C}$, secondary carbides of the $\mathrm{M}_{23} \mathrm{C}_{6}$ type precipitate in the $\mathrm{Cr}$ supersaturated primary austenite matrix $^{[6,21,22]}$ and they will appear in all the samples together with the new transformed phase during cooling.

The single-phase transformation occurring at low temperature (around $200{ }^{\circ} \mathrm{C}$ ) in Figure 3(a), can be related to the $\mathrm{Ms}$ transformation due to the relatively high cooling rate of $1{ }^{\circ} \mathrm{C} / \mathrm{s}$, and therefore, the matrix microstructure is expected to be martensite with some fraction of retained austenite (RA), which was detected by XRD, as shown in Figure 5.

This TT cycle represents the commonly used destabilization process followed by quenching, which is applied with the aim of precipitating secondary carbides and transforming the primary austenitic matrix to martensite. The size and fraction of secondary carbides, as well as the amount of retained austenite will depend on the destabilization time and temperature. ${ }^{[2]}$ The secondary carbides, as shown in Figure 5(d), were identified as $\mathrm{M}_{23} \mathrm{C}_{6}$ with a fcc lattice structure, ${ }^{[6,21]}$ which were precipitated during TT cycle on the grain boundaries (larger SC) and within the grains (smaller SC). The difference in size and precipitation sites of the secondary carbides might indicate that the precipitation occurred at different stages of the heat treatment. ${ }^{[22]}$ Some authors have described the precipitation of different types of SC during destabilization as a function of $\mathrm{Cr} / \mathrm{C}$ ratio of the $\mathrm{HCCI} .^{[6,7,21-23]} \mathrm{For} \mathrm{Cr} / \mathrm{C}>6.8$, as is the case in this work $(\mathrm{Cr} / \mathrm{C}=10.5)$, the precipitation of $\mathrm{M}_{23} \mathrm{C}_{6}$ is expected, whereas for lower $\mathrm{Cr} / \mathrm{C}$ ratios, precipitation of $\mathrm{M}_{7} \mathrm{C}_{3}$ has been reported after the material being subjected to destabilization and quenching $\left(\sim 3{ }^{\circ} \mathrm{C} /\right.$ min). The precipitation of $\mathrm{M}_{3} \mathrm{C}$ during the destabilization stage is not expected in $\mathrm{HCCI}$, since the $\mathrm{Cr}$ content and other carbide forming elements hinder their formation, and besides, the destabilization temperature is too high for allowing the nucleation and growth of this type of carbides.

The sample cooled at $0.13{ }^{\circ} \mathrm{C} / \mathrm{s}$ showed two phase transformations (at $\sim 700{ }^{\circ} \mathrm{C}$ and $\sim 200{ }^{\circ} \mathrm{C}$, Figure $3(\mathrm{~b})$ ) and thus, it is expected for the matrix to be composed of more than one phase, martensite and ferrite/carbides in the form of pearlite, as indicated in Figure 6. This is supported by metallographic analysis where different grey levels in OM and SEM images (Figures 6(a) and (c)) indicate different etching rates for different phases. Furthermore, the secondary carbides embedded in both martensite and ferrite matrix can be observed in
Figure 6(d). The secondary carbides are mostly of the $\mathrm{M}_{23} \mathrm{C}_{6}$ type precipitated during the destabilization cycle, as shown before for the sample cooled at $1{ }^{\circ} \mathrm{C} / \mathrm{s}$. Additionally, in some areas of the samples, it is possible to observe very small and thin carbides showing a rod-like shape, which might correspond to $\mathrm{Fe}_{3} \mathrm{C}$ carbides. In the diffractogram of Figure 6(b), the different phases present in the sample can be observed. $\mathrm{Fe}_{3} \mathrm{C}$ was not detected, since the fraction might be too low for the detection limits of the techniques, whereas the ferrite peak is detected superimposing on those corresponding to martensite and $\mathrm{M}_{7} \mathrm{C}_{3} \mathrm{EC}$.

Finally, a complete matrix transformation to ferrite/carbides is expected in the sample with the lowest cooling rate $\left(0.02{ }^{\circ} \mathrm{C} / \mathrm{s}\right)$ due to the presence of only one high temperature transformation in the dilatometric curve (Figure 3(c)). Thus, a matrix containing a single-phase composed of ferrite and carbides in the form of pearlite is expected. In Figure 7(b), it is evident that the intense peak corresponds to ferrite, and Figure 7(d) shows the $\mathrm{M}_{23} \mathrm{C}_{6}$ secondary carbides together with the characteristic shape of the $\mathrm{Fe}_{3} \mathrm{C}$ carbides forming pearlite. ${ }^{[2]}$ Thereby, the difference in size of the $\mathrm{M}_{23} \mathrm{C}_{6}$ secondary carbides might be related to their precipitation at different stages of the thermal cycle. ${ }^{[22]}$

Analysis of the microstructure by OM gives a first indication of the phases present in the microstructure. As expected, the eutectic carbides $\left(\mathrm{M}_{7} \mathrm{C}_{3}\right)$ which remain unchanged by heat treatments were present in all the specimens, whereas the matrix phase was composed differently. The secondary carbides were not properly revealed with this method due to the low magnification and resolution of $\mathrm{OM}$.

Metallography and phase analysis corroborate the results obtained from the dilatometric measurements for all the samples. They showed the unaffected EC of the $\mathrm{M}_{7} \mathrm{C}_{3}$ type, secondary carbides of the $\mathrm{M}_{23} \mathrm{C}_{6}$ and $\mathrm{Fe}_{3} \mathrm{C}$ types, and different matrix structures depending on the cooling rate applied (Figure 8).

It is worth to mention that some difficulties occurred during the phase indexing of the diffraction peaks. The first point of difficulty arises during the separation of the ferrite/martensite peak. They can be differentiated considering the peak broad and position. Since martensite usually presents high density of crystal defects, the martensite peaks are broader than ferritic peaks and their position is shifted to lower angles. ${ }^{[7,25]}$ On the other hand, the $\mathrm{M}_{23} \mathrm{C}_{6}$ and $\mathrm{Fe}_{3} \mathrm{C}$ secondary carbides are not possible to be unambiguously identified, since their phase fraction is too low compared to the matrix and eutectic carbides and thus, their diffraction peaks are located within the background noise. Moreover, the peaks for the different carbide types overlap making their identification arduous. For these reasons, combining different characterization techniques, such as SEM and XRD are highly valuable for the identification of secondary carbides.

The carbides of the $\mathrm{Fe}_{3} \mathrm{C}$ type are not easily observed in the sample cooled at $0.13^{\circ} \mathrm{C} / \mathrm{s}$. One of the reasons might be related to the austenite decomposing in different stages, as described by References 14 and 16 where the austenite starts transforming to ferrite and 

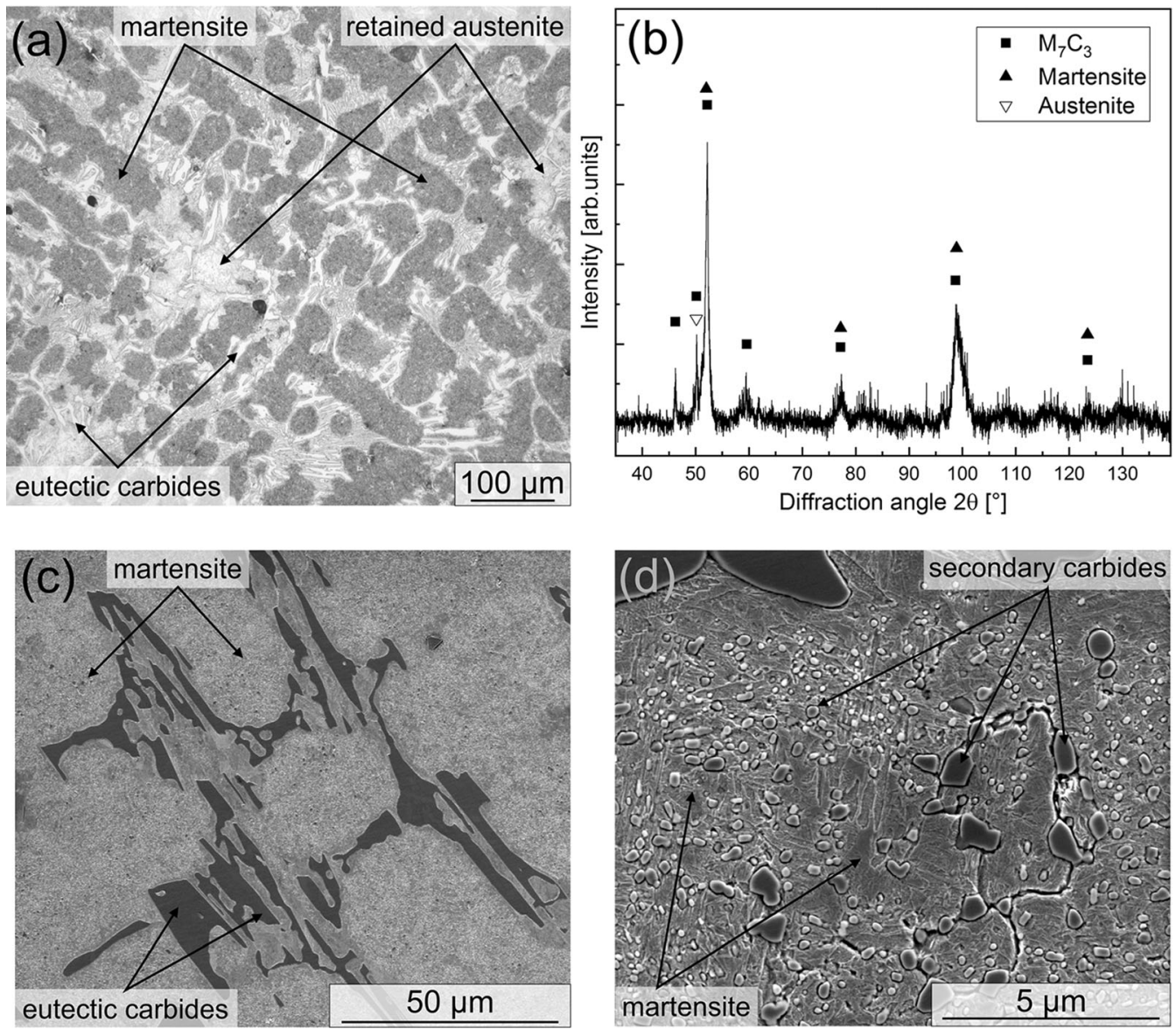

Fig. 5-Phase and microstructural characterization of the sample cooled at $1{ }^{\circ} \mathrm{C} / \mathrm{s}$. (a) $\mathrm{OM}$ image; (b) diffractogram in the range between 35 and $140 \mathrm{deg}$, showing the presence of martensite, austenite and $\mathrm{M}_{7} \mathrm{C}_{3}$ carbides corresponding to the EC; $(c)$ SEM micrograph, 1000 times magnification; and (d) SEM micrograph, 10,000 times magnification, where the secondary carbides of the $\mathbf{M}_{23} \mathrm{C}_{6}$ type are visible. Diffraction peaks were indexed according to powder diffraction files from the ICDD database. The different phases in the micrographs are indicated by arrows.

later to pearlite due to the carbon enrichment of the austenite and the subsequent precipitation of cementite. The cooling rate might be sufficient enough for suppressing the formation of pearlite.

\section{B. Construction of TTT Diagrams}

The temperatures for the isothermal experiments were selected based on the phase transformation boundaries of the CCT diagram (Figure 4) in the range of $640{ }^{\circ} \mathrm{C}$ to $740{ }^{\circ} \mathrm{C}$. The thermal profile applied to the samples is the one described in Figure 2(b). The boundaries for the isothermal phase transformation are shown in Figure 9. The longest times for the starting and finishing of the transformation correspond to the highest $\left(740{ }^{\circ} \mathrm{C}\right)$ and lowest $\left(640{ }^{\circ} \mathrm{C}\right)$ temperatures, whereas the shortest time was observed for the intermediate temperature $\left(680^{\circ} \mathrm{C}\right)$, resulting in the typical nose-shaped diagram. The mean values of the corresponding times for the defined fractions between 5 and 95 pct were plotted together with their error bars as a function temperature and detailed in Table III. For each isothermal temperature, the critical times were marked and connected by dashed lines, which represent the isofraction boundaries in the TTT diagram of Figure 9.

The deviation of the critical averaged values shown in Figure 9 and Table III might be based on many sources. The samples were machined with an error in the final length of $\pm 0.15 \mathrm{~mm}$. Some dimensional variations in diameter have no influence on the detection of the dilatometric curve. However, the length might influence the detection of the dimensional changes, since the samples are held between two quartz push rods with a fixed spacing and thus, the samples might be compressed differently, affecting the detection. While this parameter has a large influence on soft materials, marginal error is expected for the material under investigation. ${ }^{[26]}$

The inhomogeneity of the material is another important factor contributing to the results' dispersion. As seen in Figure 1, inhomogeneity exists in the microstructure and chemical composition of the HCCI_26 pet $\mathrm{Cr}$ with regions of high and low density of eutectic carbides. The different phases present different specific volumes and therefore, the change in length will be influenced by the fraction of each phase contained within the dilatometric specimen. 

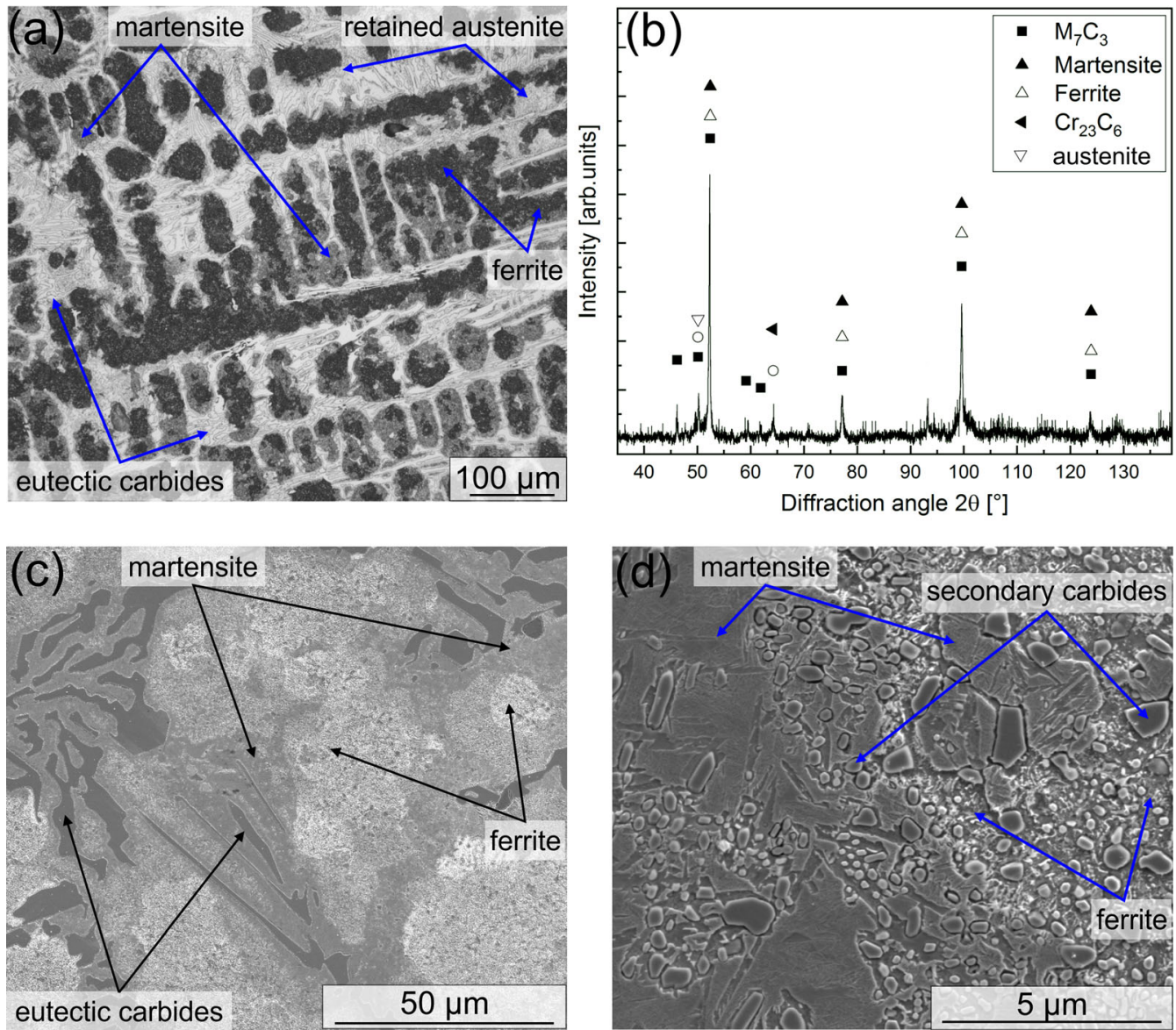

Fig. 6-Phase and microstructural characterization of the sample cooled at $0.13{ }^{\circ} \mathrm{C} / \mathrm{s}$. (a) $\mathrm{OM}$ image; (b) diffractogram in the range between 35 and $140 \mathrm{deg}$, showing the presence of martensite, ferrite, austenite, $\mathrm{M}_{23} \mathrm{C}_{6}$ and $\mathrm{M}_{7} \mathrm{C}_{3}$ carbides corresponding to the SC and EC, respectively; (c) 1000 times magnification SEM micrograph; and (d) 10,000 times magnification SEM micrograph where the secondary carbides of the $\mathrm{M}_{23} \mathrm{C}_{6}$ type are visible. Diffraction peaks were indexed according to powder diffraction files from the ICDD database. The different phase in the micrographs are indicated by arrows.

A TTT diagram of a HCCI with similar chemical composition (2.95 pet C- 0.02 pct Mn-25.8 pet Cr) as the one tested in this work was presented by Maratray et $a{ }^{[20]}$ In this TTT diagram the shortest time needed for a complete phase transformation was set at $700{ }^{\circ} \mathrm{C}$, starting after 250 seconds and finishing after 1200 seconds. The different temperature and time values in correspondence with the present work $\left(680{ }^{\circ} \mathrm{C}\right.$; 200 and 1050 seconds for transformation starting and finishing, respectively, according to Figure 9) can be related to difference in the chemical composition and to the previous thermal history. Moreover, the transformed phase fraction was analysed visually by $\mathrm{OM}$, providing a large error in the determination of the transformed phase fraction. But in general, the diagrams created by Maratray et al. ${ }^{[20]}$ are comparable to a certain extent with the ones developed in this study.

1. Microstructural and phase analysis of TTT sample

Only one sample isothermally treated was selected for the microstructural and phase characterization, since all of the samples were maintained until complete transformation and then cooled down to room temperature. For this purpose, the sample treated at $680{ }^{\circ} \mathrm{C}$ held for 4000 seconds, i.e. fully transformed, was selected. After the transformation, the matrix is completely ferritic with the presence of secondary carbides in the form of pearlite, as shown in Figure 10. Again, the presence of $\mathrm{M}_{23} \mathrm{C}_{6}$ secondary carbides can be noticed in Figure 10(d), which were precipitated during the destabilization stage.

The TT applied to the samples for the construction of the TTT diagram simulate the sub-critical diffusion treatment shown by Guitar et al. ${ }^{[7]}$ In many cases, this subcritical treatment (tempering) is implemented for reducing the retained austenite content after destabilization and increase the resistance to spalling. ${ }^{[2]}$ Attention must be paid to the parameters during tempering, since very long times might lead to a softening of the material and thus, a reduction of the abrasion resistance. ${ }^{[2]}$ In the work presented by Guitar et al. ${ }^{[7]}$ it was shown that austenitizing and quenching the samples after the sub-critical treatment leads to an improvement in the wear resistance. It was suggested that the size of 

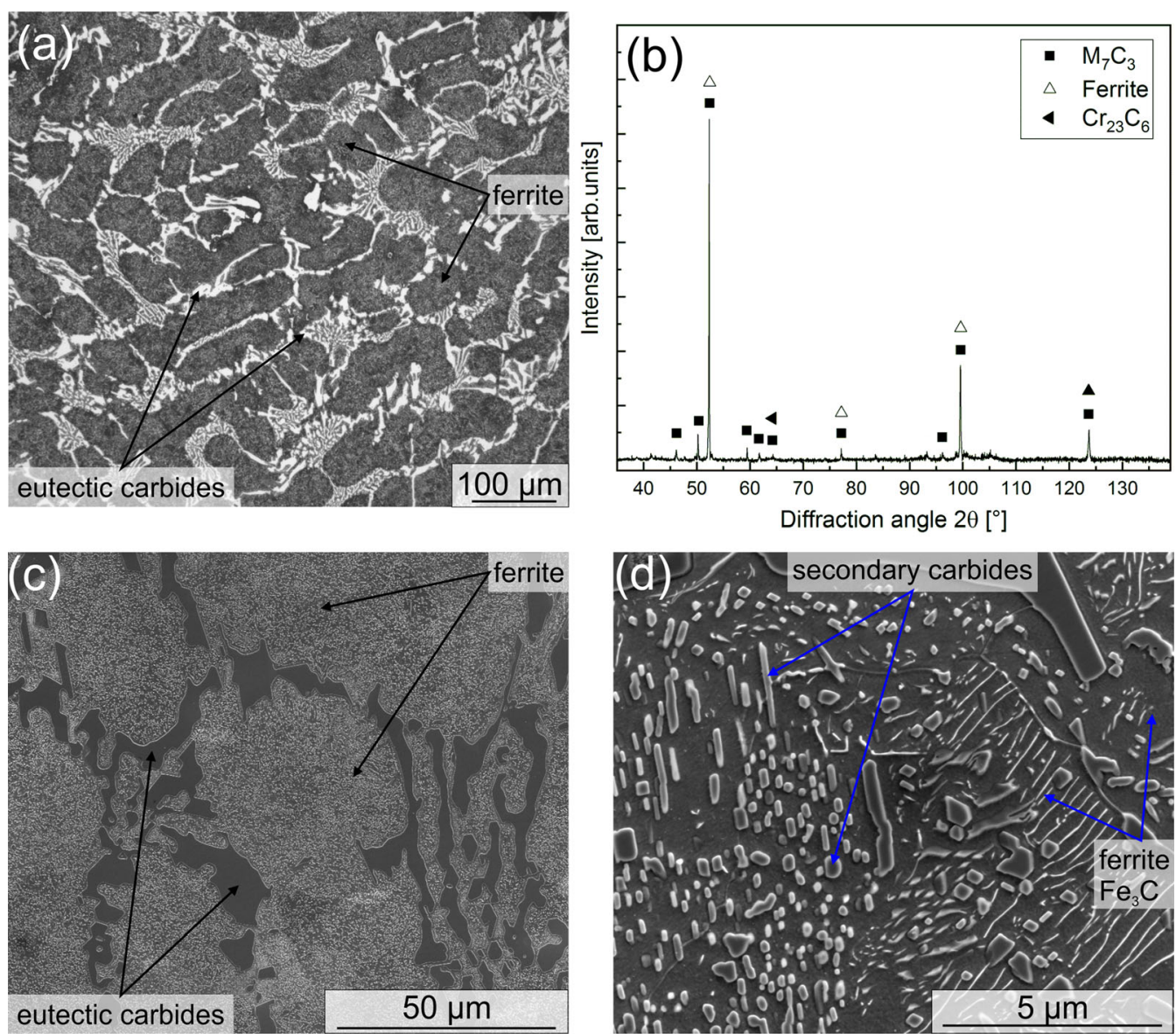

Fig. 7-Phase and microstructural characterization of the sample cooled at $0.02{ }^{\circ} \mathrm{C} / \mathrm{s}$. $(a) \mathrm{OM}$ image, 200 times magnification; $(b)$ diffractogram in the range between 35 and $140 \mathrm{deg}$, showing the presence of ferrite, and $\mathrm{M}_{23} \mathrm{C}_{6}$ and $\mathrm{M}_{7} \mathrm{C}_{3}$ carbides corresponding to the SC and $\mathrm{EC}$, respectively; (c) 1000 times magnification SEM micrograph; and (d) 10,000 times magnification SEM micrograph where the secondary carbides of the $\mathrm{M}_{23} \mathrm{C}_{6}$ and $\mathrm{Fe}_{3} \mathrm{C}$ type are visible. Diffraction peaks were indexed according to powder diffraction files from the ICsDD database. The different phase in the micrographs are indicated by arrows.
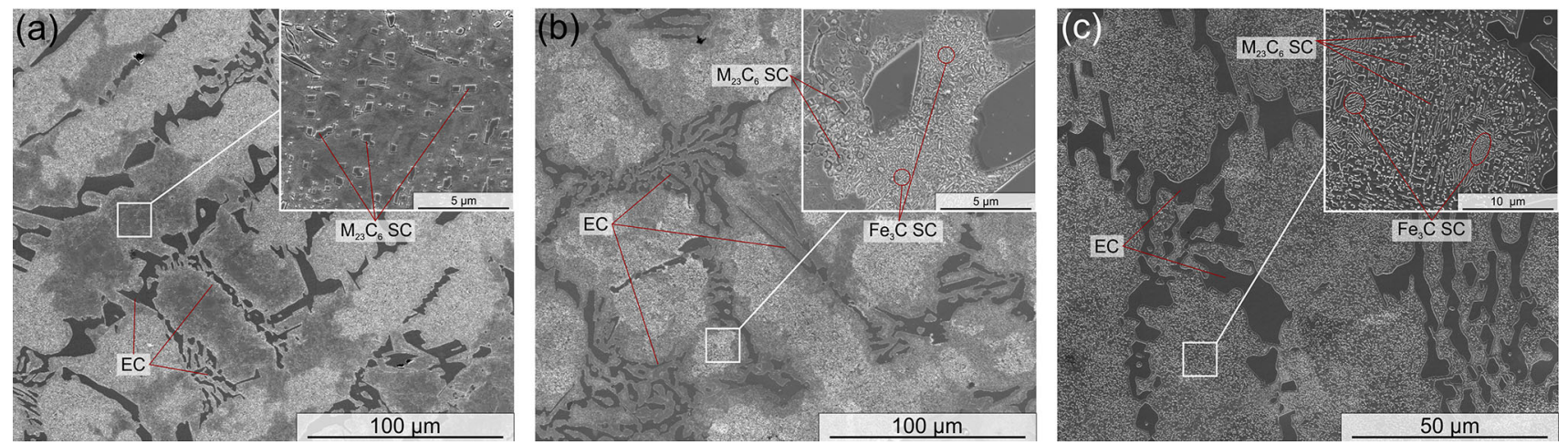

Fig. 8- SEM images corresponding to the samples cooled at different cooling rates: $(a) 1{ }^{\circ} \mathrm{C} / \mathrm{s}$, the EC and $\mathrm{SC}$ of the $\mathrm{M}_{23} \mathrm{C}_{6}$ type embedded in a martensitic (darker grey) and ferritic (lighter grey) matrix are identified; (b) $0.13{ }^{\circ} \mathrm{C} / \mathrm{s}$, EC and $\mathrm{SC}$ of the $\mathrm{M}_{23} \mathrm{C}_{6}$ and $\mathrm{Fe}_{3} \mathrm{C}$ embedded in a martensitic (darker grey) and ferritic (lighter grey) matrix are identified; (c) $0.02{ }^{\circ} \mathrm{C} / \mathrm{s}$, EC, and $\mathrm{SC}$ of the $\mathrm{M}_{23} \mathrm{C}_{6}$ and $\mathrm{Fe}_{3} \mathrm{C}$ embedded in a fully ferritic matrix are identified.

the secondary carbides was the predominant parameter influencing this behaviour. However, the supporting matrix should also play an important role in the increasing of the wear resistance, since it is subjected to several changes during the SCD step. After this step, the matrix is essentially ferritic with precipitated $\mathrm{SC}$ $\left(\mathrm{M}_{7} \mathrm{C}_{3}\right.$ for HCCI_16 pctCr and $\mathrm{Fe}_{3} \mathrm{C}+\mathrm{M}_{23} \mathrm{C}_{6}$ for HCCI_26 pctCr), as shown in Reference 7 and in 


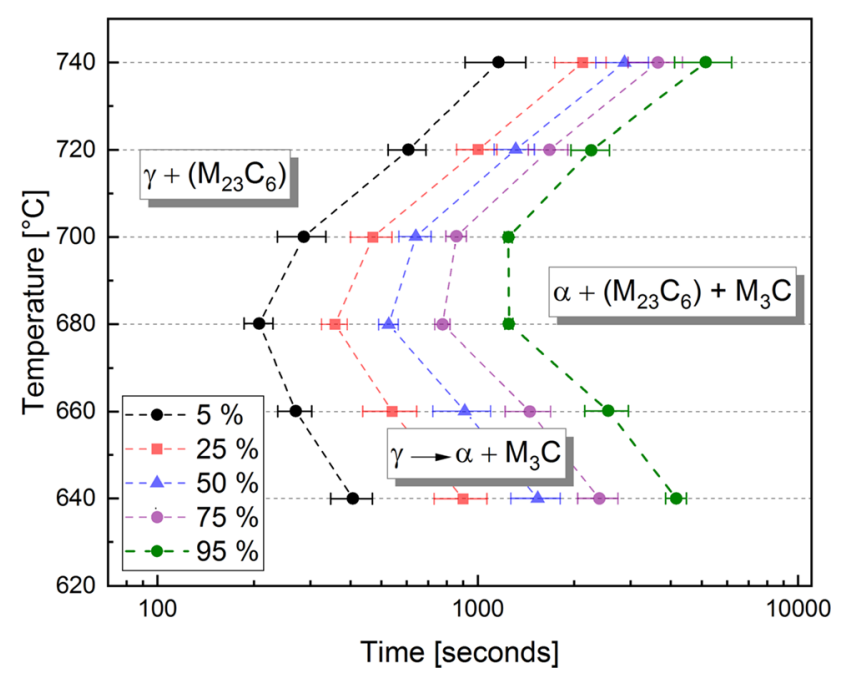

Fig. 9-TTT diagram constructed on the basis of Fig. 1(b).

Figure 10. The transformation to ferrite produces refined, strain-free grains, which might improve the toughness. ${ }^{[27]}$

\section{Experimental verification}

The goal of the experimental verification was to prove that the transformation boundaries in Figure 9, represent a good approximation for the phase transformation behaviour of HCCIs containing 26 wt pet chromium. Therefore, three samples were heat treated in the laboratory to experimentally verify the results obtained by dilatometry. The samples were held at $640{ }^{\circ} \mathrm{C}$ for different times, as indicated in Table III, in order to obtain specific fractions of the transformed phase $(25,50$ and $75 \mathrm{pct}$ ). After the TT, the samples were metallographically prepared according to Section II and analysed by OM, SEM and XRD according to Section II-A.

The phase fraction of the transformed phase is indicated in Table IV. Some deviation of the transformed phase can be observed in comparison to the expected one. They might be related to a combination of different experimental errors. For instance, the holding times for obtaining a certain fraction was selected from the TTT diagram (Figure 9), which already shows a deviation. Furthermore, for the experimental validation two furnaces, set at $980{ }^{\circ} \mathrm{C}$ and $640{ }^{\circ} \mathrm{C}$, were used and the sample transfer from one to another results in a different cooling rate $\left(\sim 0.93{ }^{\circ} \mathrm{C} / \mathrm{s}\right)$ as that used during dilatometry $\left(2.8^{\circ} \mathrm{C} / \mathrm{s}\right)$. It is known that the cooling rate might influence the transformation parameters and therefore lead to a deviation in the determined transformed phase fraction. ${ }^{[28-30]}$ Finally, the phase fraction determination by means of image analysis has always some level of subjectivity ${ }^{[31]}$ and thus, the results are influenced by the author's judgement. In the case of using OM images, the sample from Figure 10(a), was used as reference for the calculation of the EC fraction. As this fraction might vary for different images, the final calculated fraction values might show some error. This source of error is much smaller when SEM images are used, since the contrast between the different phases is good and thus, the fraction of EC was calculated for each image independently.

Figure 11 shows diffractograms corresponding to the different phase fractions. An increase in the ferrite peak can be observed. Figure 11(d) illustrates the variation in the ferrite peak for the different samples. In the sample $640{ }^{\circ} \mathrm{C} \_25$ pct, a high fraction of non-transformed austenite results in martensite after the cooling, which is indicated by the wideness of the peak and the lower intensity with respect to the others. Finally, the peak corresponding to the $640{ }^{\circ} \mathrm{C}_{-} 75$ pct is the most sharp and intense, indicating a larger amount of ferritic phase diffracting in this condition.

It has been argued that the lever rule approach is valid if a single, non-partitioning phase transformation occurs. For complex systems such as high alloyed steels, this method might not be applicable due to the alloy element partitioning, which might cause the remaining austenite to change in composition and therefore, in volume. In case of carbon-containing alloys, the carbon redistributes between the remaining austenite and the forming ferrite, increasing the specific volume of the austenite, and due to the formation of pearlite, which has a different volume effect than the ferrite formation. ${ }^{[14,16,32]}$ In this case, when the material transforms to a multi-phase region (ferrite/carbides), the lattice transformation occurs together with a redistribution of alloying elements. With respect to HCCI, the complexity of the material is such that a redistribution of alloying elements is expected to occur at more than one point of the thermal cycle. For instance, during the SC precipitation in the destabilization stage, the austenite will be depleted in carbon and alloying elements. This effect will occur during heating or holding as a consequence of nucleation and growth of SC. During cooling, the austenite will gradually transform into ferrite, and the remaining austenite will enrich in carbon. The final expansion of the sample will be affected by both the formation of ferrite and the carbon enrichment of the austenite. ${ }^{[14,16]}$ Upon cooling the sample further, austenite will decompose into pearlite/cementite (pearlite), where the volume effect from the formation of ferrite and pearlite differ from each other. In some cases, the formation of ferrite and pearlite takes place in separated temperature regions, and the transformation of each phase can be evaluated separately. ${ }^{[16,28]}$

When the lever rule is used for the transformed phase calculation in HCCI, the formation of a single phase was assumed, and the length change of the sample is assumed to be proportional to the fraction of this phase. That means that the effect of carbon enrichment of the austenite can be neglected, and that the atomic volumes of ferrite and pearlite are equal. ${ }^{[16]}$ Moreover, in the present work, the application of the lever rule seems to be appropriated, as demonstrated by the experimental verification in Section III-B-2. The experimentally calculated fraction of transformed phases give a good approach to the values calculated from the dilatometric curves using the lever rule, suggesting that the austenite to ferrite/carbides (pearlite) transformation can be considered as a single-phase transformation. It was observed that by increasing carbon concentrations, the 
Table III. Time Corresponding to Phase Fraction $\left(\gamma \rightarrow \alpha+\mathbf{M}_{3} \mathrm{C}\right)$ Transformed at the Different Isothermal Transformation Temperatures

\begin{tabular}{lcccccc}
\hline \multirow{2}{*}{$\begin{array}{l}\text { Transformed Phase }\left(\gamma \rightarrow \alpha+\mathrm{M}_{3} \mathrm{C}\right) \\
(\mathrm{Pct})\end{array}$} & \multicolumn{5}{c}{ Time for the Isothermal Transformation at the Different Temperatures (s) } \\
\cline { 2 - 7 } & $640{ }^{\circ} \mathrm{C}$ & $660{ }^{\circ} \mathrm{C}$ & $680{ }^{\circ} \mathrm{C}$ & $700{ }^{\circ} \mathrm{C}$ & $720^{\circ} \mathrm{C}$ & $740{ }^{\circ} \mathrm{C}$ \\
\hline 5 & $407 \pm 61$ & $270 \pm 33$ & $207 \pm 21$ & $285 \pm 49$ & $607 \pm 82$ & $1161 \pm 249$ \\
25 & $899 \pm 168$ & $541 \pm 103$ & $358 \pm 33$ & $470 \pm 69$ & $1003 \pm 144$ & $2127 \pm 388$ \\
50 & $1538 \pm 269$ & $910 \pm 186$ & $527 \pm 37$ & $640 \pm 74$ & $1313 \pm 189$ & $2871 \pm 537$ \\
75 & $2395 \pm 345$ & $1452 \pm 234$ & $776 \pm 43$ & $858 \pm 63$ & $1673 \pm 236$ & $3649 \pm 704$ \\
95 & $4168 \pm 311$ & $2553 \pm 398$ & $1250 \pm 37$ & $1245 \pm 36$ & $2263 \pm 312$ & $5153 \pm 1038$ \\
\hline
\end{tabular}

The cells in italics indicate the points used for the experimental verification (Section III-B-2).
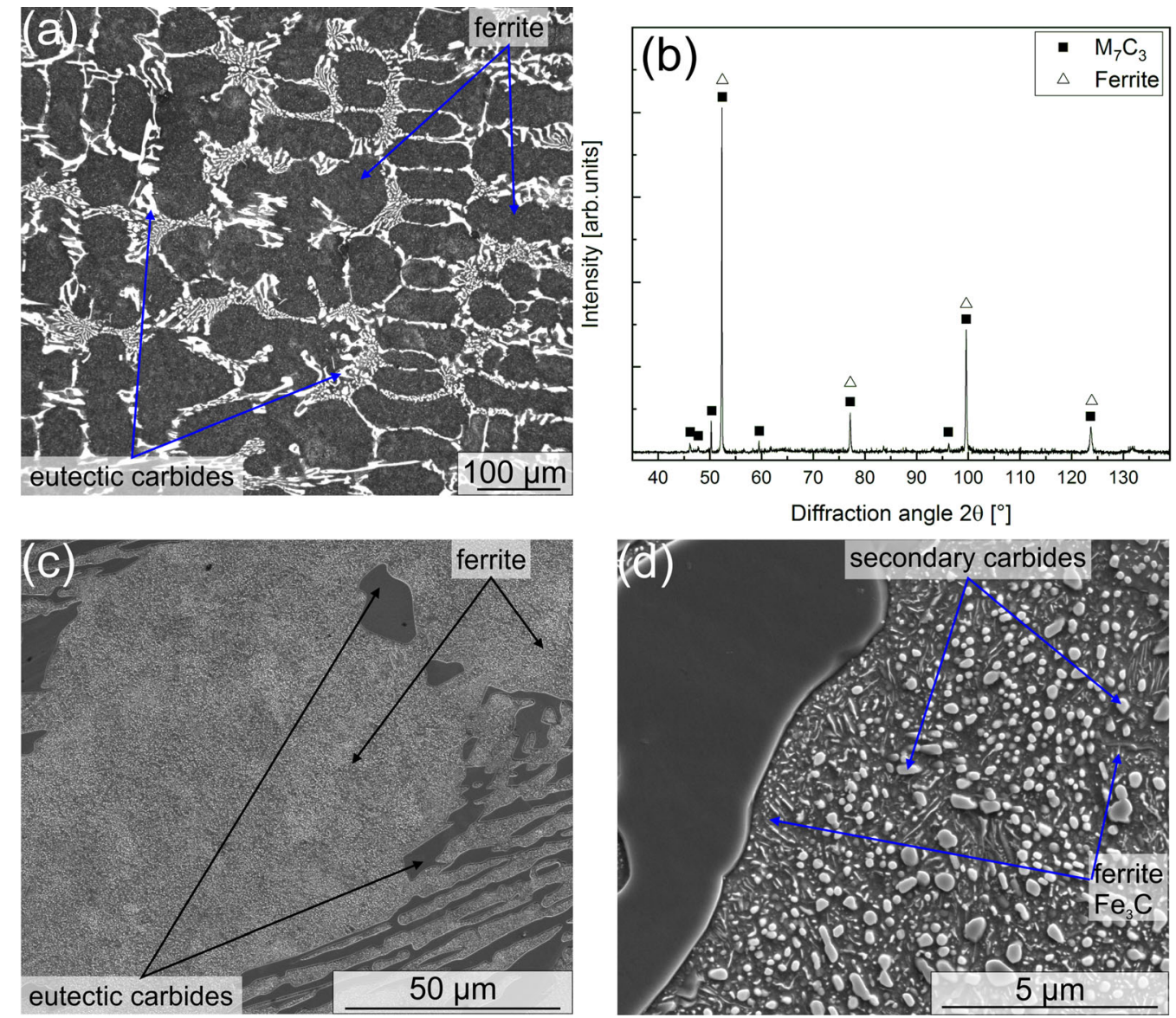

Fig. 10-Phase and microstructural characterization of the sample isothermally treated at $680{ }^{\circ} \mathrm{C} .(a)$ OM image; (b) diffractogram in the range between 35 and 140 deg, showing the presence of ferrite, and $\mathrm{M}_{7} \mathrm{C}_{3}$ carbides corresponding to the EC; $(c) 1000$ times magnification SEM micrograph; and (d) 10,000 times magnification SEM micrograph where the secondary carbides of the $\mathrm{M}_{23} \mathrm{C}_{6}$ and $\mathrm{Fe}_{3} \mathrm{C}$ type can be appreciated. Diffraction peaks were indexed according to powder diffraction files from the ICDD database. The different phase in the micrographs are indicated by arrows.

Table IV. Phase Fraction of the Transformed Phase Calculated by IA from OM and SEM Images

\begin{tabular}{llll}
\hline Sample & $640_{25}(\mathrm{Pct})$ & $640_{50}(\mathrm{Pct})$ & $640_{75}(\mathrm{Pct})$ \\
\hline Fraction OM & $23.8 \pm 0.8$ & $57.0 \pm 0.4$ & $80.4 \pm 0.9$ \\
Fraction SEM & $22.2 \pm 1.7$ & $56.6 \pm 1.3$ & $74.7 \pm 1.2$ \\
\hline
\end{tabular}

fraction of formed ferrite decreases ${ }^{[16]}$ and that might be the reason for the good implementation of the lever rule in the phase transformation of HCCI. It can be assumed that lever rule gives the amount of transformed austenite and does not give information about individual fraction of ferrite and pearlite. 

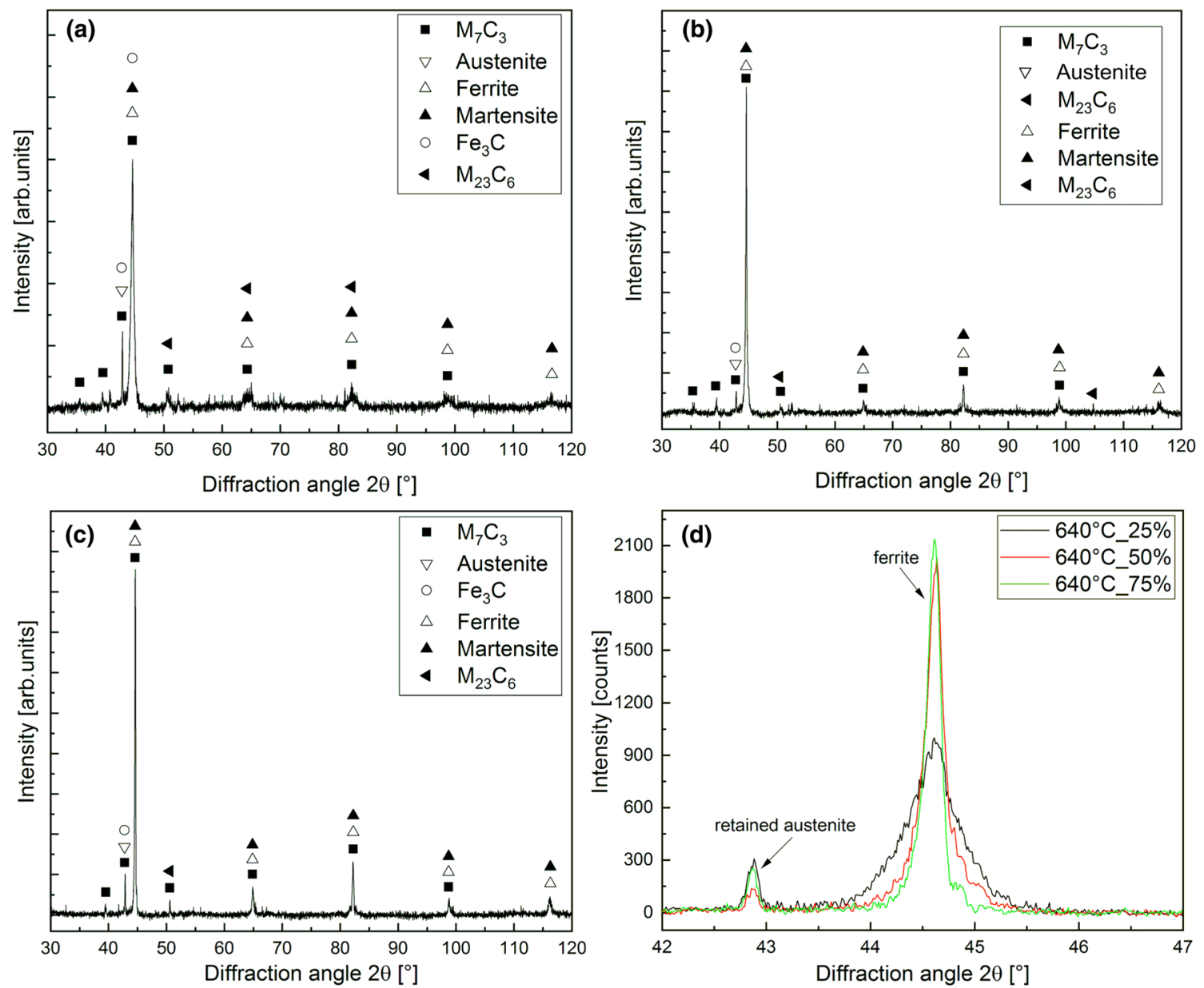

Fig. 11-Phase characterization of the samples isothermally heat treated at $640{ }^{\circ} \mathrm{C}$ for different times: $(a) 900 \mathrm{~s}$ for obtaining 25 pct phase transformation; (b) $1540 \mathrm{~s}$ for $50 \mathrm{pct}$ phase transformation; $(c) 2400 \mathrm{~s}$ for 75 pct phase transformation; and (d) comparison of the ferrite/ austenite peak variation as a function of the transformed phase. The diffractograms were measured using $\mathrm{Cu} \mathrm{K} \alpha$ radiation.

\section{CONCLUSIONS}

By applying dilatometric measurements, it was possible to establish the boundaries of phase transformations for different cooling rates in a CCT diagram for a HCCI containing 26 wt pet $\mathrm{Cr}$. Based on this diagram, a TTT diagram was constructed by destabilizing the samples and then isothermally holding until complete phase transformation. Experimental laboratory verification of the TTT diagram was done by heat treating 3 samples at $640{ }^{\circ} \mathrm{C}$, isothermally being held for 3 different times. In all cases, the transformed phase fractions were determined using the lever rule method.

During the continuous cooling, one or more breaks in the dilation curve were observed as a function of the cooling rate, which were related to the phase transformations. For the fastest cooling rates $\left(1{ }^{\circ} \mathrm{C} / \mathrm{s}\right.$ and $0.2{ }^{\circ} \mathrm{C} /$ s), only one phase transformation occurred at a relatively low temperature, which was identified by XRD and metallographic analysis as the formation of martensite. On the other hand, two transformations were identified at intermediate cooling rates $\left(0.13{ }^{\circ} \mathrm{C} / \mathrm{s}\right)$ one at high temperature (between $600{ }^{\circ} \mathrm{C}$ to $700{ }^{\circ} \mathrm{C}$ ) and other at low temperature $\left(\sim 200{ }^{\circ} \mathrm{C}\right)$, which correspond to the formation of ferrite and carbides (in the form of pearlite), and martensite, respectively.

The final microstructure of the heat-treated samples showed SC of the $\mathrm{M}_{23} \mathrm{C}_{6}$ type precipitated during the destabilization stage, as demonstrated by XRD, SEM and $\mathrm{OM}$ after analysing the sample cooled at $1{ }^{\circ} \mathrm{C} / \mathrm{s}$. Furthermore, the $\mathrm{M}_{23} \mathrm{C}_{6} \mathrm{SC}$ were present together with $\mathrm{SC}$ of the type $\mathrm{Fe}_{3} \mathrm{C}$ in samples cooled at lower cooling rates, as a consequence of the decomposition of the austenite into ferrite and pearlite.

The TTT diagram was constructed from dilatometry data by performing isothermal treatments between 640 ${ }^{\circ} \mathrm{C}$ and $740{ }^{\circ} \mathrm{C}$ after destabilization (980 $/ 1.5$ hours). Experimental phase fraction determined by image analysis from OM and SEM images showed a good correlation with the phase fractions calculated from the dimensional changes using the lever rule.

The phase transformation boundaries given by the CCT and TTT diagrams calculated from dilatometry techniques, will serve as a first approach for the design and optimization of heat treatments for the microstructure tailoring in HCCI, leading to a reduction of the 
experimental work needed for the microstructural design, resulting in a reduction of time and resources necessary for a successful tailored microstructure.

\section{ACKNOWLEDGMENTS}

Open Access funding provided by Projekt DEAL. The authors want to thank Martin Müller for the constructive discussion and to Dr.-Ing. Martin Duarte from Tubacero S.A. for providing the material. M.A.G., A.S., D.B. and F. M. wish to acknowledge the EFRE Funds (C/4-EFRE-13/2009/Br) of the European Commission for support of activities within the AME-Lab project.

\section{CONFLICT OF INTEREST}

The authors declare that they have no conflict of interest.

\section{OPEN ACCESS}

This article is licensed under a Creative Commons Attribution 4.0 International License, which permits use, sharing, adaptation, distribution and reproduction in any medium or format, as long as you give appropriate credit to the original author(s) and the source, provide a link to the Creative Commons licence, and indicate if changes were made. The images or other third party material in this article are included in the article's Creative Commons licence, unless indicated otherwise in a credit line to the material. If material is not included in the article's Creative Commons licence and your intended use is not permitted by statutory regulation or exceeds the permitted use, you will need to obtain permission directly from the copyright holder. To view a copy of this licence, visit http://creat ivecommons.org/licenses/by/4.0/.

\section{REFERENCES}

1. P. Amorim, H. Santos, J. Santos, S. Coimbra, and C. Sá: Mater. Sci. Forum, 2004, vols. 455-456, pp. 290-94.

2. K. Abdel-Aziz, M. El-Shennawy, and A.A. Omar: Int. J. Appl. Eng. Res., 2017, vol. 12, pp. 4675-86.

3. H. Gasan and F. Erturk: Metall. Mater. Trans. A Phys. Metall. Mater. Sci., 2013, vol. 44A, pp. 4993-5005.

4. D. Kopyci, E. Guzik, D. Siekaniec, and A. Szcz: Arch. Foundry Eng., 2014, vol. 14, pp. 43-46.
5. A. Wiengmoon, J.T.H. Pearce, and T. Chairuangsri: Mater. Chem. Phys., 2011, vol. 125, pp. 739-48.

6. S.D. Carpenter, D. Carpenter, and J.T.H. Pearce: Mater. Chem. Phys., 2007, vol. 101, pp. 49-55.

7. M.A. Guitar, S. Suárez, O. Prat, M. Duarte Guigou, V. Gari, G. Pereira, and F. Mücklich: J. Mater. Eng. Perform., 2018, vol. 27 , pp. $3877-85$.

8. G.L.F. Powell and G. Laird: J. Mater. Sci., 1992, vol. 27, pp. 29-35.

9. C.P. Tabrett, I.R. Sare, and M.R. Ghomashchi: Int. Mater. Rev., 1996, https://doi.org/10.1179/imr.1996.41.2.59.

10. ASM Handbook Vol. 4-Heat Treating, 1997.

11. A.E. Karantzalis, A. Lekatou, and H. Mavros: J. Mater. Eng. Perform., 2009, vol. 18, pp. 174-81.

12. Ö.N. Doğan, J.A. Hawk, and G. Laird: Metall. Mater. Trans. A, 1997, vol. 28A, pp. 1315-28.

13. K.H. ZumGahr and D.V. Doane: Metall. Trans. A, 1980 , vol. $11 \mathrm{~A}$, pp. $613-20$

14. M. Takahashi and H.K.D.H. Bhadeshia: J. Mater. Sci. Lett., 1989, vol. 8, pp. 477-78.

15. U.P. Nayak, M.A. Guitar, and F. Mücklich: Metals, 2020, vol. 10, art. no. 30, https://doi.org/10.3390/met10010030.

16. T.A. Kop, J. Sietsma, and S. Van Der Zwaag: J. Mater. Sci., 2001, vol. 36 , pp. 519-26.

17. M.A. Guitar, A. Scheid, D. Britz, and F. Mücklich: Pract. Metallogr., 2019, vol. 56, pp. 1-16.

18. M.A. Guitar, A. Scheid, S. Suárez, D. Britz, M.D. Guigou, and F. Mücklich: Mater. Charact., 2018, vol. 144, pp. 621-30.

19. C. García De Andrés, F.G. Caballero, C. Capdevila, and L.F. Álvarez: Mater. Charact., 2002, vol. 48, pp. 101-11.

20. F. Maratray and Usseglio-Nanot R.: Atlas-Transformation Characteristics of Chromium and Molybdenum White Iron, Climax Molybdenum S.A. Paris, 1971.

21. E. Karantzalis, A. Lekatou, and H. Mavros: Int. J. Cast Met. Res., 2009, vol. 22, pp. 448-56.

22. M.A. Guitar, U.P. Nayak, D. Britz, and F. Mücklich: Int. J. Met., 2020, https://doi.or/10.1007/s40962-020-00407-4.

23. A. Inoue and T. Masumoto: Metall. Trans. A, 1980, vol. 11, pp. 739-47.

24. D.A. Porter and K.E. Easterling: Phase Transformations in Metals and Alloys, 2nd ed., Chapman \& Hall, London, 1992.

25. Z.H. Cong, N. Jia, X. Sun, Y. Ren, J. Almer, and Y.D. Wang: Metall. Mater. Trans. A, 2009, vol. 40A, pp. 1383-87.

26. M. Jankula, P. Sín, R. Podoba, and J. Ondruška: Anyagtechnológia Mater. Technol., 2013, vol. 65, pp. 11-14.

27. J.O. Agunsoye and A.A. Ayeni: Tribol. Ind., 2012, vol. 34, pp. 82-91.

28. T. Liu, M. Long, H. Fan, D. Chen, H. Chen, H. Duan, W. Jiang, and W. He: J. Mater. Res., 2018, vol. 33, pp. 967-77.

29. A. Verma, M. Sundararaman, J.B. Singh, and S.A. Nalawade: Meas. Sci. Technol., 2010, https://doi.org/10.1088/0957-0233/21/ $10 / 105106$.

30. C. Samuel and S. Viswanathan: Int. J. Met., 2008, vol. 2, pp. 55-63.

31. P. Suwanpinij, N. Togobytska, C. Keu, W. Weiss, U. Prahl, and D. Homberg: Mater. Technol., 2008, vol. 79, pp. 793-99.

32. E.B. Hawbolt, B. Chau, and J.K. Brimacombe: Metall. Trans. A, 1985, vol. 16A, pp. 565-78.

Publisher's Note Springer Nature remains neutral with regard to jurisdictional claims in published maps and institutional affiliations. 